\title{
Spirals and 'Twists of Negro Hair
}

\section{By Dr. J. E. Duerden, Wool Industries Research Association, Leeds}

$\mathrm{T}$ HE hair of the Negro, Bantu and related races takes the form of short, curly tufts, with an entanglement of interlacing whorled and looped fibres and loose broken fragments, an absence of any orderly arrangement giving the hair its characteristic frizziness. The fibres are very variable in thickness $(40-80 \mu)$ and usually show breakage phases towards the free end, frequent fragmentations serving to keep the hair short. In cross section they are highly elliptical $(1: 1 \cdot 4)$, finer and thicker intervals, just visible to the naked eye, corresponding with the

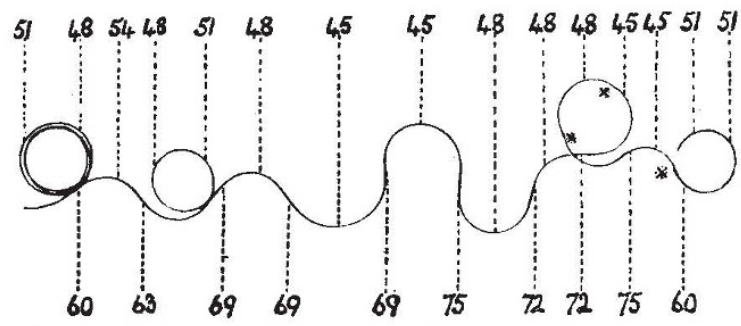

FIG. 1. Photograph of Negro hair, $\times 3$, showing whorls and loops and measurements $(\mu)$ of minor and major axes ; ${ }^{*}$ are places of breakage.

minor and major axes displayed where the fibre is twisted. Samples taken from the West African Negro, and South African Hottentot, Swazi and Xosa* show no significant differences. On close study, certain structural peculiarities are revealed which serve to interpret the characters mentioned and have a bearing upon the forms assumed by mammalian hair generally.

When single fibres are drawn out of the entanglement and partly straightened, each resolves itself into a grouping of one or more spiral whorls of approximately equal radius (helical, D'Arcy Thompson, 1917), alternating with loops of various sizes, in which any definite spiral arrangement is obscure (Fig. 1). Also when viewed in the plane of the microscope, the major and minor axes are represented as different thicknesses in the fibre, and indicate where the axial twists occur. As seen in the measurements on the figure, the whorls display only the minor axis, as also the crests and troughs of the loops, while the major axis appears at each side of the loops.

The fibre rotator indicates that at any one point an axial turn from the minor to the major axis, or vice versa, represents $90^{\circ}$, while one of $180^{\circ}$ represents a complete half turn, that is, from one aspect of the major or minor axis to the opposite. Moreover, a single half turn $\left(180^{\circ}\right)$ brings about a reversal in the direction of a whorl, while two half turns are involved in the production of a complete loop and restoration of the original direction.

Two chief factors evidently contribute to the peculiarities of the Negro hair : a fundamental spiral growth of the fibres, upon which is impressed an axial twist at regular or irregular intervals. The twists produce reversals in the direction of turn of the spiral, sinistral or dextral ; a twist of $180^{\circ}$ gives a single reversal, one of $360^{\circ}$ restores the original direction. An interval of growth between two consecutive twists leaves the fibre in its primary spiral form of one or more whorls, whereas a close succession of twists gives a periodic series of loops or crimps, disposed in no regular plane. It is these variations in the twists of the individual fibre which bring about the frizziness of the Negro hair as a whole. They are structural, not something impressed upon it from the outside, just as is the dark pigment of the hair and the skin. Owing to their diversity of form and position, the spirals and loops of the different fibres cannot dispose themselves in any regular fashion as regards one another, as in the production of curls or locks in the white races, where the fibres arrange themselves with some degree of parallelism. Occasionally in the Negro the tufts display a not very successful attempt to form short helical curls.

The structural characteristics of the hair of the ulotrichous races suggest a comparison with the diverse forms of hair occurring in mammals generally, and particularly with the fleece of the sheep, so much studied at the present time. As before, most of the conditions met with can be interpreted on the basis of a spiral growth of the fibre associated with axial twist. As pointed out by Nichols ${ }^{1}$ and others, comparatively few fibres are straight and appear of even thickness throughout their length. In the plane of the microscope most show thickenings and thinnings, usually accompanied by bends and waves; some of these may be due to metabolic differentiation during growth, but most are found to be associated with the twisting of an elliptical structure, and the presentation to view of the axes of different width. Their prevalence may well cause reflection as to the value of the ordinary microscopic measurements of fibres. Variations in form and apparent differences in thickness along the length of the fibres have been found in a wide series of mammals examined and call for fuller treatment. It appears not unlikely that the relationship of spire and twist will be found to be general throughout the hair of mammals.

The birth coat in most breeds of sheep consists of spiral tufts of fibres (prototrichs) with free fibres between, somewhat as in Negro hair. The tufts are helical or

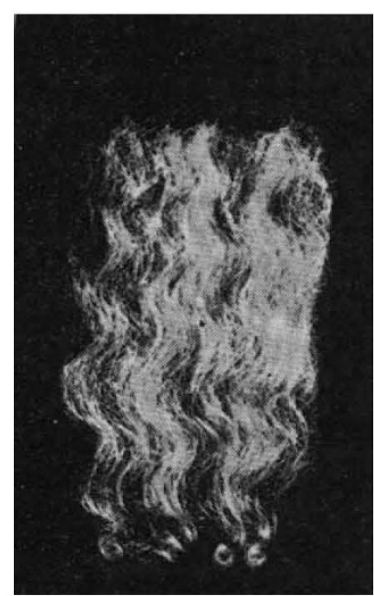

FIa. 2. Wool from Border Leices ter lamb, 3 months, showing the helical spirals of the birth-coat above and the stapled, crimped, deflnitive wool below. corkscrew spirals, scarcely increasing in radius from one end to the other, and differ much in the closeness or separation of the whorls, while one or more reversals in the direction of turn usually occur. After birth the fleece changes its character. The spiral tufts are continued into more or less flattened staples, the individual fibres grouped into small strands and assuming an almost uniplanar wavy or crimped form (Fig. 2). Some breeds, like the Wensleydale and Dartmoor, and the Angora, retain to a large 
degree the original spiral form of the birth tufts, the adult fleece consisting of long, separate curls or ringlets; others, such as the Cheviot, may lose all the spiral or wavy regularity and take on a loosely matted, frizzy character, as in the Negro.

Fine Merino wool shows the extreme of regularity in crimp formation; the number has been found to vary inversely with the thickness of the fibre and to be a periodic function of time. Among wool problems, probably not one has been more fully discussed than that of the production of crimps, but it is manifest from the above that they are of the same nature as the loops in Negro fibres, and are therefore to be interpreted as a periodic series of twists and reversals impressed on a spiral foundation. Hence the change from the spiral tufts of the birth coat to the crimped definitive coat of the adult, with suppression of the spiral form, is to be associated with the axial twisting of the fibres. The spiral is transformed by a regular succession of mechanical twists and reversals into a periodic series of crimps, which give to wool much of its textile value.

By means of the fibre rotator Rossouw ${ }^{2}$ has shown that in each complete wave or crimp there are two twists and two reversals of $180^{\circ}$, the minor axis always showing at the crest and the trough of the wave and the major axis along each side.

The constructive factors involved in the production of the spiral growth of the fibre and its frequent reversals, as well as the regular or irregular incidence of the axial twist, are not yet fully understood. S. G. Barker ${ }^{3}$ has shown that they may be interpreted as resulting from two simple harmonic forces acting at right angles, but the biological nature of these forces is not yet clear. That the crimps are to be associated with the primarily spiral, axially twisted condition of the fibres, clarifies the problem. A complete crimp is seen to represent an axial twist of $360^{\circ}$, and in the plane of the microscope exhibits two minor and two major axes. Both vary in number inversely with the thickness of the fibre and are a periodic function of time.

* Dr. S. G. Barker has further obtained from Dr. O. L. Mohr, Oslo, samples of the hair occurring in the Norwegian family recently mentioned in NATURE, 133, 695, May 13, 1933. Under his direction these have been fully stndied hy Miss A. L. Walker, by means of the fibre rotator, and the measurements expressed in graphic form. Apart from their reduced pigmentation, thev are found to conform in every way with hair from the typical ulotrichous races.

1 Nature, 131, Feb. 11, 1933.

2 J. Text. Inst., 22, July 1931.

${ }^{3}$ Trans. Farad. Soc., 29, January 1933.

\section{Cultural History in Middle America*}

A NEW series of publications, appearing under the title Ibero-Americana, is to be issued by the University of California, which will form a complement to the "Publications in American Archæology and Ethnology" already published by that body. It will consist of studies in Latin-American cultures, native and transplanted, pre-European, colonial and modern. Physical and racial backgrounds are to have a place in the series, but it is anticipated that the studies, in the main, will be contributions to culture history. There will be no regular date for publication, and each issue will be independent and individually paged, its price varying according to size. The editors are Dr. Herbert E. Bolton, Prof. A. L. Kroeber and Dr. C. O. Sauer.

The scope and character of the series may be gauged from the first three numbers which have been published. Broader in scope than the archæological series of publications, this series, if continued on present lines, promises to be of considerable interest to students of American culture.

In "Aztatlán", Dr. Carl Sauer and Mr. Donald Brand describe a previoúsly unrecorded culture in Sinaloa and Nayarit. The culture area is situated in a shallow strip of country on the Pacific coast of Mexico, which stretches from the valley of the Rio Grande de Santiago at the south to Culiacán in the north. This is the Terra Caliente of Guzman's Nueva Galicia, for which the oldest regional term is Aztatlán. In this area, more than thirty mounds were visited, probably only a small fraction of the total number which exists. All are situated either on flood plains or on their margins, the inconveniences of the situation being indicated by the number of artificial mounds on which the habitations once stood. Most of those in the Culiacán valley do not exceed three to four feet in height; but the

*Ibero-Americana. 1: Aztatlán, Prehistoric Mexican Frontier on the Pacific Coast. By Carl Sauer and Donald Brand. Pp. 92 (14 plates). 2 dollars. 2 : The Comparative Ethnology of Norther Mexico before 1750. By Ralph L. Beals. Pp. vi +93-226. 1.35 dollars. 3: The Road to Cíbola. By Carl Sauer. Pp. iv +58 . 75 cents. (Berkeley, Calif.: University of California Press, 1932.) largest in the Presidio valley is some thirty feet high.

The general character of the culture is purely southern. The district would appear to have acquired its culture well back in the Toltecan period and is pre-Aztecan in character. Culiacán forms a frontier facing north. The whole area is a long north-western tongue of prehistoric Mexican culture. It does not rate high in stone carving; but the stone implements have distinctive qualities. The culture is excellent in pottery making, the ware being thin, tough, of fine paste and highly polished. It has a basic colour decoration in parallel banding but with engraving as its most characteristic feature. This is applied equally to monochrome and polychrome.

The population would appear to have been almost completely destroyed in the early Spanish occupation by Guzman in 1530 .

The discovery of the Aztatlán culture was made while the authors were seeking evidence for the existence of a prehistoric corridor between the Mexican highland and the Pueblo country of the south-western States, a problem upon which both the second and the third studies in this series also have a direct bearing. No. 3 "The Road to Cíbola", which here may be dismissed in a few words, traces the course followed by the early Spanish conquerors towards the north-west in their search for a legendary city of fabulous wealth. The interest of the study lies in the fact that their way lay along the main trails beaten by many generations of Indian travel which later became the historic highways, forging a link between the prehistoric past and the modern present.

The third study, "The Comparative Ethnology of Northern Mexico before 1750", bears even more directly on the problem of the relation of the SouthWestern Pueblos to Middle and South America. Dr. Ralph L. Beals has extracted from early Spanish sources the evidence relating to the culture of the area of northern Mexico which lies between the United States frontier and a line drawn from the mouth of the Rio Panuco to the southern boundary 